\title{
Different modalities in management of acute scahphoid fracture
}

\author{
S.A.Khalil, M.I.Mostafa, S.A.Shoulah and M.E.Mohamed
}

Orthopedic Surgery, Dept., Faculty of Medicine, Benha Univ., Benha, Egypt

E-mail: Essam@yahoo.com

\begin{abstract}
Background . Background Scaphoid fractures constitute around 2-3\% of all fractures and about $10 \%$ of all the fractures in the hand. The indication of closed treatment of fractures with scaphoid is generally confined to stable fractures without displacements. Kirschner wires, screws and staples incorporate operational approaches. Both flying and dorsal methods have been documented as percutaneous methods (pins and cannulated screws). Purpose The objective of the research is to undertake a comprehensive analysis of previous available research on various ways of managing acute scaphoid fractures. Patients and procedures The search for literature was done using PubMed, SCOPUS, Web of Science, and the Cochrane Library. Search and filtering literature produced 7 full text publications (254 patients), randomised controlled trials were included. Results Surgical fixation on scaphoid fractures results in better rates of union and quick union times of 5 to 9 weeks. As for casting, the union usually takes around 7 to 16 weeks and the union rate is between 85 and 90\%. ROM 90 percent -97 percent following conservative scaphoid fracture therapy, whereas surgical therapy was 88 percent - 97 percent. Grip strength was $88 \%-98 \%$ improvement with conservative therapy and 84\%-94\% following surgical therapy. The return to work was surgery for 6-8 weeks before, but for those who were receiving conservative therapy it was 415,5 weeks. Conclusion Our analysis showed no statistically significant difference in overall complications between surgical and non-operative therapy. However, independent study demonstrated that surgical therapy had the benefit of delayed union, backed by time-to-fracture union analyses.
\end{abstract}

Keywords: Scaphoid fractures, surgical management, nonsurgical management. Egypt Orthop the Egyptian Orthopaedic Association.

\section{Introduction}

The scaphoid plays a significant part in the function of the wrist and is a major link in the next row of the carpus. The articular cartilage that should be addressed in the treatment of scaphoid fractures is covering more than two-thirds of the surface of the scaphoid [1].

The major blood supply is derived from the palmar and dorsal artery branches, however only retrograde flow supplies the proximal section. So untreated saphoid fractures of the proximal poles have a significant incidence of nonunion [2]

Scaphoid fracture is the most frequent carpal fracture, accounting for $60 \%$ of all carpal fractures, $10 \%$ of all fractures in the hands and $2 \%$ of all fractures. An second ipsilateral hand or wrist fracture is seen in five percent of individuals with scaphoid fractures. There is a male dominance $(82$ per cent) between 10 and 30 years with a peak agespecific incidence [3].

In situations with prolonged nonunion, the skaphoid nonunion may evolve to advanced wrist breakdown and arthritis, which may necessitate a salvage treatment and consequently anatomical fracture union efforts may be repeated if necessary. As new kinds of surgeries such as the different vascularized bone grafts are employed for treating scaphoid nonunion [4].

The most prevalent cause of scaphoid waist fracture is hyperextension with axial stress following a fall on a stretched hand. A direct strike to the Scaphoid tuber commonly during a drop might result in a distal divide, which is the most frequent divide in children [5].
Following clinical assessment of the patient e.g. for discomfort in the anatomical snuffbox area, a precise radiological approach is required to identify and diagnose the fracture [6]. Scaphoid fractures (dorsopalmar, lateral and Stecher views) are generally identified, however some fractures remain X-ray oculary. A computed tomography bone scan (CT) is used to confirm the diagnosis in individuals with a high clinical risk of a scaphoid fracture. The easiest technique to check fracture and any accompanying deformation is to make a sagittal incision, parallel to the $0,5-1 \mathrm{~mm}$ long axis of the scaphoid [7].

Most scaphoid fractures have been treated with a Paris plaster for at least 6 weeks conservatively. If the fracture is treated during acute therapy, 85-95\% will reach a union after 6-12 weeks of plaster therapy, however the union rate will fall after $>4$ weeks of therapy [8].

Factors such as fracture site or degree of dislocation are increasingly shown to impact the time and probability of union. The proximal pole has a poor blood supply anatomically, and this has been believed to affect the healing period since the arteries have to retrogradely propagate from distal to proximal across the fracturing line when the pole is proximal. A proximal polar fracture is the least prevalent location for fractures (6-10 percent) [9].

The rationale for closed treatment for scaphoid fractures is generally agreed to be largely restricted to stable non-dislocated distal third and scaphoid waist fractures[10]. Operational stabilisation is necessary for displaced, comminuted or unstable 
scaphoid fractures. The typical approach is open reduction and internal fixation.

In 1954, McLaughlin was the first to report a surgical treatment of a scaffold fracture employing a vitallium screw to support the scaffold broken. Different types of hardware have been created and utilised: K-wires, lags, Ender tubes and staples; however the invention by Herbert and Fischer in the late 1970s of a double-threaded twin-pitch headless screw and its clinical introduction in 1984 have made surgical treatment increasingly popular [11].

With the union rates approaching to 100 percent, the results of minimally invasive fixing in both displaced and displaced fractures was promising. This is without the lengthy period of immobilisation and disadvantages such as rigidity, reduced grip force, probable skin issues and working disability [12].

\section{Material and Methods}

Step (1) data sources and search strategy.

The literature search was done using the following electronic databases: PubMed, SCOPUS, Web of Science, and The Cochrane Library. The search strategies were developed and edited by the authors to maximize the sensitivity. The search strategy included several different terms and synonyms for scaphoid bone fractures and nonsurgical management and surgical management in combination with, rehabilitation, complications, functional outcome and return to work.

Step (2) selection of studies.

First, all titles and abstracts were screened for the following criteria: Article concerned (1) a clinical study and (2) included patients who have Giant cell tumor of bone which is primary or recurrent. Moreover, (3) only articles in the English language were considered for inclusion in this review. For all selected titles and abstracts, the fulltext articles were gathered for further screening. Screening of full-text papers included the first three criteria supplemented with the following criteria: the study was (4) confined to acute scaphoid fractures who underwent surgery or conservative treatment.

Step (3) study characteristics.

The following study characteristics were systematically extracted from the selected full-text papers: author, year of publication, intervention types (nonoperative and operative procedures), study design (Randomized controlled trials, or Clinical trials Phase II), the number of patients in each non operative treatment, surgical intervention group, age and duration of the follow-up (mean and SD or median and range), functional outcomes of each intervention, complications and return to work.

Step (4) outcomes of the included studies.

The following outcome characteristics and scores were systematically extracted from the selected full-text papers, union rate, Complications, range of motion, grip strength, functional outcome, and return to work.

\section{Results}

Our initial literature search retrieved 98 unique records. Following title and abstract screening, 51 full text articles were retrieved for further scrutiny. Finally, 7 full text articles (254 patients) were included in our final analysis Fig. (1).

The summary of the design illustrated in Table (1), while the baseline characteristics of enrolled studies are illustrated in Table (2) The mean age of patients who underwent acute scaphoid fractures during these studies was 39.4 years old.

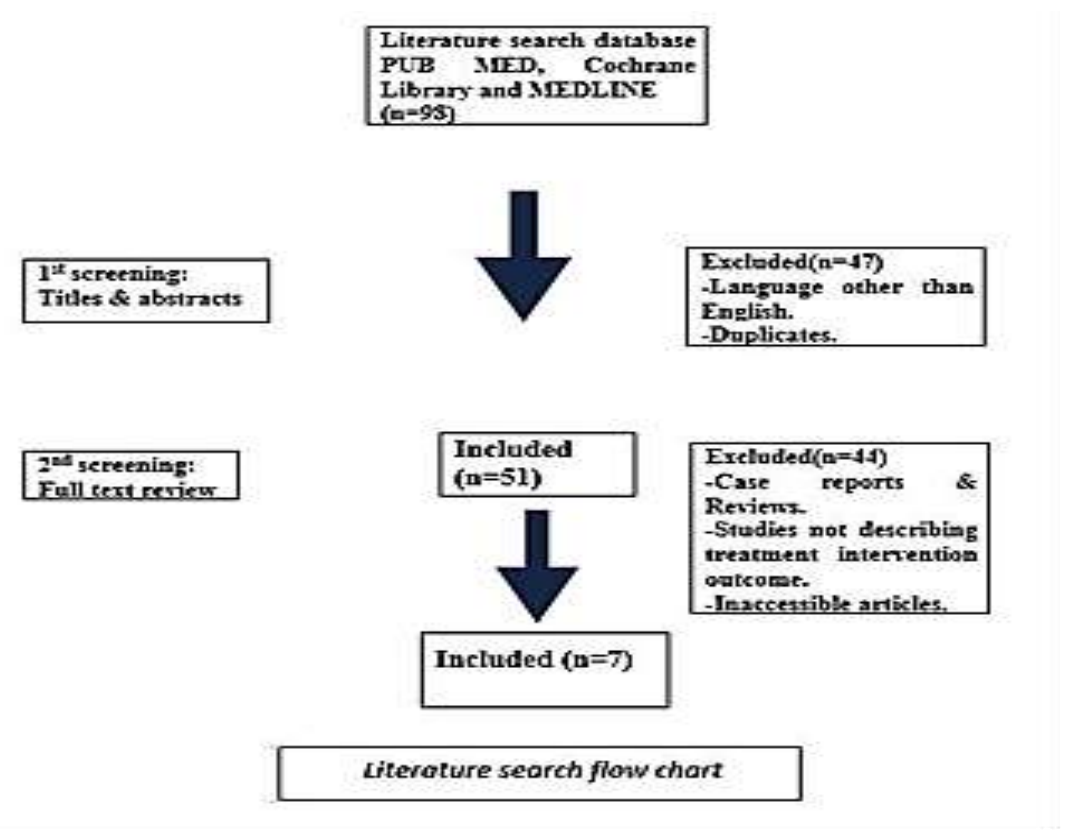

Fig. (1) Literature search flow chart. 
Among 254 patients enrolled in 7 papers which discussed the distribution of gender in their studies there were 198 male patients, 56 female patients with a proportion of $77.9 \%$ to $22 \%$ male to female respectively table (3).

the most common location of fracture was wrist fracture (B2) 76 cases with average $70.2 \%$ followed by distal oblique fracture (B1) 12 cases with the rate of $11.7 \%$, proximal pole fracture (B3) 8 cases with the average of $7.4 \%$, Trans scaphoid perilunate dislocations (B4) 3 cases with the average of $2.5 \%$ table (4).

The duration of fracture union as mentioned in two studies. It has been noted that surgical fixation for scaphoid fractures yields higher union rates and rapid union time as 5 weeks to 9 weeks. As for casting, it typically takes around 7 to 16 weeks for union, with percentage of $85-90 \%$ of union rate table (5).

The different duration of follow-up of the seven included studies ranging from at least 8 weeks to 9 years is a general source of heterogeneity. Two studies reported that the primary outcome measurement, functional outcome, mainly improved over time between 8 and 52 weeks of follow-up table (6).

Table (1) Summary of study design.

\begin{tabular}{lll}
\hline Authors & Year & Type of the study \\
\hline Mcqueen et al[13] & 2008 & Randomized control trial \\
Dias et al[14] & 2011 & Randomized control trial \\
Robertson et al[15] & 2012 & Retrospective cohort study \\
Robertson et al[16] & 2014 & Case series \\
Clementson et al[17] & 2015 & Randomized control trial \\
Patil et al[18] & 2020 & Randomized prospective study \\
Mohamed SA et al[19] & 2021 & Non-Randomized Clinical Study \\
\hline
\end{tabular}

Table (2) Baseline characteristics of enrolled studies.

\begin{tabular}{lll}
\hline Authors & \multicolumn{2}{l}{ Year No of patients Mean Age in years (range) } \\
\hline Mcqueen et al[13] & 200860 & $29.4(17-65)$ \\
Dias et al[14] & 201188 & $33(16-61)$ \\
Robertson et al[15] & 201220 & $26.1(24-45)$ \\
Robertson et al[16] & 20142 & $21(20-61)$ \\
Clementson et al[17] & 201538 & $34(18-62)$ \\
Patil et al[18] & 202020 & $39(18-89)$ \\
Mohamed SA et al[19] & 202126 & $40.1(18-64)$ \\
\hline
\end{tabular}

Table (3) Gender distribution.

\begin{tabular}{lll}
\hline Authors & Year Male/ female & Mean Age in years (range) \\
\hline Mcqueen et al[13] & $200831 / 7$ & $29.4(17-65)$ \\
Dias et al[14] & $201150 / 10$ & $33(16-61)$ \\
Robertson et al[15] & $201262 / 26$ & $26.1(24-45)$ \\
Robertson et al[16] & $201420 \mathrm{M}$ & $21(20-61)$ \\
Clementson et al[17] & $20152 \mathrm{M}$ & $34(18-62)$ \\
Patil et al[18] & $202012 / 8$ & $39(18-89)$ \\
Mohamed SA et al[19] & $202121 / 5$ & $40.1(18-64)$ \\
\hline
\end{tabular}

Table (4) Type of fracture.

\begin{tabular}{lc}
\hline Authors & Fracture type \\
\hline Mcqueen et al[13] & B1 (1)- B2 (54) \\
Dias et al[14] & - \\
Robertson et al[15] & B1 (5)- B2 (11)- B3 (4) \\
Robertson et al[16] & B1 (1)- B2 (1) \\
Clementson et al[17] & - \\
Patil et al[18] & - \\
Mohamed SA et al[19] & B1 (5)- B2 (10)- B3 (4)- B4 (3) \\
\hline
\end{tabular}


In four studies showed the Range of motion after conservative treatment of scaphoid fracture was $90 \%-97 \%$ while operative treatment was $88 \%$ $97 \%$. According to regaining grip strength, it was $88 \%$ - $98 \%$ improvement with conservative treatment and $84 \%-94 \%$ with surgical treatment. Return to work was earlier in patients underwent surgical management as 6-8 weeks while in those who underwent conservative treatment was 4-15.5 weeks table (7).

Table (5) method of treatment.

\begin{tabular}{|c|c|c|}
\hline Authors & Method of treatment & $\begin{array}{c}\text { No. of surgical/ conservative } \\
\text { treatment }\end{array}$ \\
\hline Mcqueen et al[13] & Immobilization in cast / acutrack screw & $30 / 30$ \\
\hline Dias et al[14] & Below elbow plaster cast / herbert screw & $44 / 44$ \\
\hline Robertson et al[15] & Conservative cast / percutaneous surgical fixation & $2 / 18$ \\
\hline Robertson et al[16] & Conservative & 2 \\
\hline Clementsoet al[17] & $\begin{array}{c}\text { Below elbow thumb spica / wrist arthroscopy and } \\
\text { antegrade screw }\end{array}$ & $14 / 24$ \\
\hline Patil et al[18] & $\begin{array}{c}\text { Glass holding scaphoid cast / percutaneous fixation } \\
\text { by herbert screw }\end{array}$ & $10 / 10$ \\
\hline $\begin{array}{l}\text { Mohamed SA et } \\
\text { al[19] }\end{array}$ & Conservative cast / operative with Herbert fixation & $13 / 13$ \\
\hline
\end{tabular}

Table (6): Rate of union and time to union after treatment.

\begin{tabular}{lcc}
\hline Authors & Rate of union & Time to union \\
\hline Mcqueen et al[13] & Conservative 23/27 & Conservative 3-9 weeks \\
surgical 27/28 & Norative 9.2 weeks \\
Robertson et al[15] & N/A & N/A \\
Robertson et al[16] & N/A & N/A \\
Patil et al[18] & - & Conservative 7-16 weeks \\
& Operative 5-9 weeks \\
Mohamed SA et al[19] & Conservative 11/15 & - \\
\hline
\end{tabular}

Table (7) follow up duration.

\begin{tabular}{lc}
\hline Authors & Follow up duration \\
\hline Mcqueen et al[13] & $8-52$ weeks \\
Dias et al[14] & $6.1-9.2$ years \\
Robertson et al[15] & $24-36$ months \\
Robertson et al[16] & $34-36$ months \\
Clementson et al[17] & $1-6$ years \\
Patil et al[18] & $6-12$ weeks \\
Mohamed SA et al[19] & 1 year \\
\hline
\end{tabular}

Table (8) Effect of surgical and conservative treatment on ROM, grip strength and return to work.

\begin{tabular}{lccc}
\hline Authors & ROM & Grip strength & Return to work \\
\hline Mcqueen et al[13] & $\begin{array}{c}\text { Conservative 90\% } \\
\text { Operative 97\% }\end{array}$ & $\begin{array}{c}\text { Conservative 99\% } \\
\text { Operative 94\% }\end{array}$ & $\begin{array}{c}\text { Conservative 15.5 weeks } \\
\text { Operative 6.4 weeks }\end{array}$ \\
Dias et al[14] & $\begin{array}{c}\text { Conservative 95\% } \\
\text { Operative 92\% }\end{array}$ & $\begin{array}{c}\text { Conservative 99\% } \\
\text { Operative 94\% }\end{array}$ & - \\
Robertson et al[14] & - & - & $\begin{array}{c}\text { Conservative 12.7 weeks } \\
\text { Operative 8.5 weeks } \\
\text { Robertson et al[15] }\end{array}$ \\
$\begin{array}{l}\text { Clementson et al[17] Conservative 97\% } \\
\text { Operative 88\% }\end{array}$ & - & Conservative 86\% & Operative 84\% \\
Patil et al[18] & - & - & $\begin{array}{c}\text { Conservative 4 weeks } \\
\text { Operative 6.6 weeks }\end{array}$ \\
\hline
\end{tabular}


Table (9) complications after treatment modalities" nonunion, avascular necrosis AVN and osteoarthritis O.A.

\begin{tabular}{|c|c|c|c|}
\hline Authors & Non union & $\mathbf{A V N}$ & O.A \\
\hline Mcqueen et al[13] & $\begin{array}{l}\text { Conservative } 4 \text { patients } \\
\text { Operative } 1 \text { patient }\end{array}$ & $\begin{array}{c}\text { Conservative } 2 \text { patients } \\
\text { Operative } 0\end{array}$ & $\begin{array}{c}\text { Conservative } 2 \text { patients } \\
\text { Operative } 0\end{array}$ \\
\hline Dias et al[14] & $\begin{array}{c}\text { Conservative } 1 \text { patients } \\
\text { Operative } 0\end{array}$ & $\begin{array}{c}\text { Conservative } 1 \text { patients } \\
\text { Operative } 0\end{array}$ & $\begin{array}{c}\text { Conservative } 3 \text { patients } \\
\text { Operative } 8 \text { patients }\end{array}$ \\
\hline Robertson et al[15] & $\begin{array}{c}\text { Conservative } 3 \text { patients } \\
\text { Operative } 0\end{array}$ & -- & -- \\
\hline Clementson et al[17] & - & - & $\begin{array}{c}\text { Conservative } 2 \text { patients } \\
\text { Operative } 3 \text { patient }\end{array}$ \\
\hline Patil et al[18] & nil & nill & nill \\
\hline Mohamed SA et al[19] & $\begin{array}{c}\text { Conservative } 4 \text { patients } \\
\text { Operative } 0\end{array}$ & - & - \\
\hline
\end{tabular}

\section{Discussion}

Scaphoid fractures mentioned in various literatures vary between 1.47 and 121 per 100,000 of the population annually and are one of the main areas of dispute in the literature on scaffolding. This is probably because to the poor capture rates, tiny population samples, the absence of a defined captive population and the limited capacity of many databases for distinguishing between a real and suspected fracture. In the future research by Saeden et al.[20] Herbert's screw attachment vs. short arm cast for acute scaphoid fractures in 61 patients with 62 fractures was compared and a short time later the operating group was reworked. There has thus been a tendency to treat these fractures surgically. [13]

Even basic therapy requires knowledge and knowledge of many treatment alternatives. A favourable forecast may be predicted if these parameters are satisfied. The McLaughlin141 and Maudsley142 advocated open reduction and internal fixation to facilitate early mobility of the acute scaphoid fracture utilising a compression lag screw. Herbert and Fischer presented the procedure for the first time in 1984 and since then the Herbert screen has been generally acknowledged as a therapy method. [21]

Acute fractures of scaphoid are commonly classed as non-displaced and displaced. Cast immobilisation is appropriate therapy for the scaphoid fracture that is not displaced [14].

Patients are treated with a protracted immobilisation of the thumb below the scaphoid plaster cast, however lately the morbidity of casting immobilisation has drawn attention [22]. The conservative treatment of non-displaced fractures does not enable a quick return to normal job and exercise. When the forearm rotates in the plaster cast, every fracture of the scaphoid might be moved from 1 to $4,0 \mathrm{~mm}$. In the event of casting and significant non-union rates, then, undisplaced scaphoid fractures may be displaced. Acute displaced casting scaphoid fractures have a significant risk of non-union and malunification of up to $50 \%$. Complications such as carpal instability, humpback deformity, joint stiffness, osteoarthritis and upper limb atrophy[23] are acute and other.

Patients with acute scaphoid fractures have surgical therapy to achieve a high fracture union rate and an early resumption to daily activities[24].

The mechanical integrity of the wrist hinges on the scaphoid's unique architecture. More than $70 \%$ of the scaphoid is cartilage covered. Its blood supply is separated into additional bones and bones. Gelberman et al. showed that the nutritional arteries that reach the dorsal crest provide about $70 \%-80 \%$ of saphoid and the tuber supplies a distal 20\%$30 \%$ of saphoid [22]. Morsy et al. revealed that the scaphoid usually contains two primary ossic infusion networks: one network entry volarily to provide the distal bone part, and the other network entering the dorsal ridge for proximal delivery. The proximal vascular network provides about 83 percent of scaphoid, whereas the distal vascular network provides 17 percent of scaphoid[25]. In retrograde flows, the primary intraosseous arteries feed the bulk of the scaphoid.

In the current study of 4 studies the most common fracture location was brace fracture (B2) 76 cases with average $70.2 \%$ followed by distal oblique fractures (B1) 12 cases with a rate of $11.7 \%$ proximal pole fracture (B3) 8 cases with an average of $7.4 \%$, trans-scaphoid perilunate dislocation (B4) 3 cases with an average number of $2.5 \%$. This was observed in accordance with the findings of the Leslie \& Dickson investigation. [26]

The varying follow-up times of the seven studies covered between at least 8 weeks and 9 years are also an overall source of variability. Two studies have revealed largely improved the key end measurement, the functional outcome, throughout time from 8 to 52 weeks of follow-up [27].

Post-immobilization and active hand and wrist functionality play a crucial part in the improvement of functionality [27]. The fact that, owing to the approach of treatment, conservatively-managed patients have a considerably shorter mobility time at the last follow-up exam results in bias in 
evaluating functional outcomes in favour of the surgeon.

The length of the fracture union is another area of concern. Operational fixation for displaced scaphoid fractures has been seen to provide greater union rates and quick union times. As for casting, the union normally takes between 9 to 12 weeks, which is why many surgeons shun the approach. [28]

However, a recent research showed that computed tomography (CT) detected scaphoid union may be attained with a short thumb spica in about 7 weeks. [28]. Two of the studies [13\&14] included employed x-rays to establish a fracture union that has low reproducibility. [14]

The time to return to work was measured in five trials. The Bond et al. Study included only of full time military personnel, which is a substantial source of variability, given their role as full-time employees. Furthermore, in other trials, the time to return to work is much less than the duration of casting immobilisation. [14] Many patients, particularly non-manual workers, may have returned to work before casting.

In a personalised approach the superiority of one treatment strategy towards the other should be assessed. Young patients and sportsmen, for example, may not endure longer immobilisation in cast, thus surgery is the preferable alternative for them which has been found to give a greater range than conservative therapy of mobility and grip strength. [14] Determination of the optimum treatment plan should be based on both patient and health system consideration. Surgical and conservative therapies place a load on the resources and public budgets of hospitals.

Economically, the surgical procedure took more than five times the direct costs of conservation therapy, yet it might be indirectly $60 \%$ less expensive than casting.

Indirect expenses may be influenced, for example, by the time necessary to return to work. [29]

Our analysis showed no statistically significant difference in overall complications between operational and non-operative therapy. Independent analyses indicated, however, that operational therapy had the benefit of delayed union, which is corroborated by time-to-fracture union study. Our results help to demonstrate that initial surgical therapy is a viable way to reduce the likelihood of postponed union after acute unreported or marginally displaced scaphoid fractures. Routine screw fixation would thus expose an unacceptable number of patients to surgical risks, particularly if a separate meta-analysis[30] as well as data from our investigation demonstrate that the risk of non-union between surgical and nonoperative therapies was not substantially different. The results of our analyses of complications differed from previous meta-analyses[30], which analysed or only carried out a combined analysis of the total rate of complications, fracture Union rate and arthritis of the Scaphotrapeziotrapezoid joint between treatment[30], including an ineligible study.

\section{Conclusion}

Our analysis showed no statistically significant difference in overall complications between operational and non-operative therapy. Independent analyses indicated, however, that operational therapy had the benefit of delayed union, which is corroborated by time-to-fracture union study.

The determination of the optimum treatment plan should be based on patient and health care system consideration. Surgical and conservative therapies place a load on the resources and public budgets of hospitals. Economically, the surgical procedure took more than five times the direct costs of conservation therapy, yet it might be indirectly $60 \%$ less expensive than casting.

\section{References}

[1] N. J.Barton, "The Herbert screw for fractures of the scaphoid.vol. 12 ,pp.517518,1996 .

[2] B. Geissler, William "Carpal fractures in athletes." Clinics in sports medicine.vol. 20.1,pp. 167-188,2001.

[3] L.M.Hove , Epidemiology of scaphoid fractures in Bergen, Norway. Scand J Plast Reconstr Surg Hand Surg.vol.33(4),pp.423 6, 1999.

[4] RM. Szabo , D. Manske Displaced fractures of the scaphoid. ClinOrthop Relat Res.vol. 230,pp.30-38, 1988.

[5] V.Vahvanen, and M. Westerlund, Fracture of the carpal scaphoid in children. A clinical and roentgenological study of 108 cases. Acta Orthop Scand .vol. 51(6),pp.909-13, 1980.

[6] N.Gibbs, R. Diamond, E O.Sekyere, W D.Thomas Management of knee osteoarthritis by combined stromal vascular fraction cell therapy, platelet-rich plasma, and musculoskeletal exercises: a case series. J Pain Res .vol. 8,pp.799-806, 2015.

[7] D J. Murray, S .Javed, N. Jain, S. Kemp, A C. Watts Platelet-rich-plasma injections in treating lateral epicondylitis: a review of the recent evidence. J Hand Microsurg . vol. 7(2),pp.320-325,2015.

[8] I.Ahmed, F.Ashton, and WK .Tay, D.Porter, The pediatric fracture of the scaphoid in patients aged 13 years and under: an epidemiological study. J Pediatr Orthop . vol .34(2),pp.150-4 , 2014.

[9] I.J.Leslie, R.A.and Dickson, The fractured carpal scaphoid. Natural history and factors influencing outcome. J Bone Joint Surg Br .vol.63-B (2,pp. 225-30, 1981. 
[10] K.Jurk , BE.Kehrel Platelets: physiology and biochemistry. Seminars in Thrombosis and Hemostasis . vol. 31(4),pp.381 -392, 2005.

[11] T.J. Herbert, and W.E. Fisher, Management of the fractured scaphoid using a new bone screw. J Bone Joint Surg Br .vol. 66(1),pp. 11 4-23, 1984.

[12] M.M.McQueen, MK.Gelbke, A.Wakefield, EM. Will, C.Gaebler, Percutaneous screw fixation versus conservative treatment for fractures of the waist of the scaphoid: a prospective randomized study. J Bone Joint Surg Br . vol. 90(1),pp.66-71, 2008.

[13] JJ.Dias, HP.Singh Displaced fracture of the waist of the scaphoid. J Bone Joint Surg Br.vol. 93(11),pp.1433-9,2011.

[14] GA. Robertson, AM .Wood, J. BakkerDyos, SA. Aitken, AC. Keenan, CM.CourtBrown The epidemiology, morbidity, and outcome of soccer-related fractures in a standard population. Am J Sports Med .vol. 40,pp.1851-1857,2012.

[15] GA. Robertson, AM. Wood, K .Heil, SA. Aitken, CM. Court-Brown The epidemiology, morbidity and outcome of fractures in rugby union from a standard population. Injury .vol. 45,pp. 677$683,2014$.

[16] M .Clementson, P .Jorgsholm, J. Besjakov, N. Thomsen, A.Bjorkman Conservative treatment versus arthroscopic-assisted screw fixation of scaphoid waist fractures: a randomized trial with minimum 4-year follow-up. J Hand Surg Am.vol. 40(7),pp.1341-8,2015.

[17] S.Nitin. Patil, Chitresh Mehta, Priyambada Kumar., Comparative Study of Functional Outcome of Minimally Displaced Scaphoid Fractures Treated by Conservative Method V/S Percutaneous Herbert Screw Fixation. AJORR.vol.4(4),pp.19-31, 2020.

[18] Mohammad Sabir Ali, Shree Prakash Singh, Vinod Kumar Singh. A Non-Randomized Clinical Study to assess the outcome of operative and non-operative treatment of Scaphoid Fracture. EJMCM.vol. 7(10),pp. 2515-8260,2020.

[19] B. Saeden, H .Tornkvist, S.,Ponzer , M. Hoglund Fracture of the carpal scaphoid; a prospective randomized 12 year follow up comparing operative and conservative treatment. J. Bone Joint Surg.vol. 83B (2),pp.230-4,2001.

[20] HL.McLaughlin , Fracture of the carpal navicular (scaphoid) bone: some observation based on treatment by open reduction and internal fixation. J. Bone Joint Surg [Am].vol. 36- A,pp.765-74,1954.

[21] G .Merrell, J . Slade Technique for percutaneous xation of displaced and nondisplaced acute scaphoid fractures and select nonunions. J Hand Surg Am .vol. 33,pp.966973,2008

[22] S.Assari, K.Darvish, andA.M. Ilyas, Biomechanical analysis of secondgeneration headless compression screws. Injury .vol. 43(7),pp. 1159-65, 2012.

[23] C.D.Bond, AY. Shin, MT. McBride, KD.Dao, Percutaneous screw fixation or cast immobilization for nondisplaced scaphoid fractures. J Bone Joint Surg Am .vol. 83-A (4),pp.483-8, 2001.

[24] M . Morsy, MD . Sabbagh, NA . van Alphen, AT. Laungani, A .Kadar, SL. Moran The Vascular Anatomy of the Scaphoid: New Discoveries Using Micro-Computed Tomography Imaging. J Hand Surg Am.vol. 44,pp.928-938,2019.

[25] IJ. Leslie, RA. Dickson The fractured carpal scaphoid. Natural history and factors influencing outcome. J Bone Joint Surg B .vol. r63-B (2),pp.225-230, 1981.

[26] R . Grewal, N. Suh, JC.MacDiarmid Is casting for non-displaced simple scaphoid waist fracture effective? A CT based assessment of union. Open Orthop J .vol .10,pp. 431-8, 2016.

[27] A.B.van der Molen , JW . Groothoff, GJ. Visser, PH .Robinson, W H.Eisma, Time off work due to scaphoid fractures and other carpal injuries in The Netherlands in the period 1990 to 1993. J Hand Surg Br.vol. 24(2),pp193-8,1999.

[28] MC. Paulus, J. Braunstein, D. Merenstein . Variability in orthopedic surgeon treatment preferences for nondisplaced scaphoid fractures: a cross-sectional survey. J Orthop.vol. 13(4),pp.337-42,2016.

[29] T. Ibrahim, A. Qureshi, AJ .Sutton, JJ.Dias Surgical versus nonsurgical treatment of acute minimally displaced and undisplaced scaphoid waist fractures: pairwise and network meta-analyses of randomized controlled trials. J Hand Surg Am .vol. 36(11),pp.1759-68 e1 , 2011.

[30] GA . Buijze, JN. Doornberg, JS. Ham, D .Ring, M. Bhandari, RW.Poolman Surgical compared with conservative treatment for acute nondisplaced or minimally displaced scaphoid fractures: a systematic review and meta-analysis of randomized controlled trials. J Bone Joint Surg Am .vol. 92(6),pp. 1534-44.152, 2010. 